\title{
Long-term outcome after allogeneic hematopoietic cell transplantation for myelofibrosis
}

\author{
Marie Robin, ${ }^{1}$ Liesbeth C. de Wreede ${ }^{2}$ Christine Wolschke, ${ }^{3}$ Johannes \\ Schetelig, ${ }^{4}$ Diderik-Jan Eikema, ${ }^{5}$ Maria Teresa Van Lint, ${ }^{6}$ Nina Simone \\ Knelange, ${ }^{7}$ Dietrich Beelen, ${ }^{8}$ Arne Brecht, ${ }^{9}$ Dietger Niederwieser, ${ }^{10}$ Antonin \\ Vitek, ${ }^{11}$ Wolfgang Bethge, ${ }^{12}$ Renate Arnold, ${ }^{13}$ Jürgen Finke, ${ }^{14}$ Liisa Volin, ${ }^{15}$ \\ Ibrahim Yakoub-Agha, ${ }^{16}$ Arnon Nagler, ${ }^{17}$ Xavier Poiré, ${ }^{18}$ Hermann Einsele, ${ }^{19}$ \\ Patrice Chevallier, ${ }^{20}$ Ernst Holler, ${ }^{21}$ Per Ljungman, ${ }^{22}$ Stephen Robinson, ${ }^{23}$ \\ Alekxandar Radujkovic, ${ }^{24}$ Donal McLornan, ${ }^{25}$ Yves Chalandon ${ }^{26}$ and Nicolaus \\ Kröger $^{3}$
}

${ }^{1}$ Hôpital Saint-Louis, APHP, Université Paris 7, Paris, France; '2Department of Biomedical Data Sciences, LUMC, Leiden, the Netherlands and DKMS CTU, Dresden, Germany; ${ }^{3}$ University Hospital Eppendorf, Hamburg, Germany; " Medizinische Klinik und Poliklinik I, Universitätsklinikum Dresden, Dresden, Germany; ${ }^{5} \mathrm{EBMT}$ Statistical Unit, Leiden, the Netherlands; ${ }^{6}$ Ospedale San Martino, Genova, Italy; ${ }^{7}$ EBMT Data Office, Leiden, the

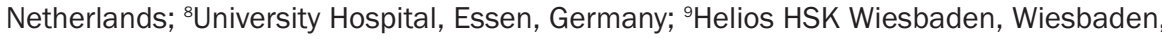
Germany; ${ }^{10}$ University Hospital Leipzig, Leipzig, Germany; ${ }^{11}$ Institute of Hematology and Blood Transfusion, Prague, Czech Republic; ${ }^{12}$ Universität Tübingen, Tübingen, Germany; ${ }^{13}$ Charité Universitätsmedizin Berlin, Berlin, Germany; ${ }^{14}$ Division of Medicine I,

Hematology, Oncology and Stem Cell Transplantation, University of Freiburg, Freiburg, Germany; ${ }^{15} \mathrm{HUCH}$ Comprehensive Cancer Center, Helsinki, Finland; ${ }^{16} \mathrm{CHU}$ de Lille, INSERM U995, Lille, France; ${ }^{17}$ Chaim Sheba Medical Center, Tel-Hashomer, Israel; ${ }^{18}$ Cliniques Universitaires St. Luc, Brussels, Belgium; ${ }^{19}$ Department of Internal Medicine II, University Hospital Würzburg, Würzburg, Germany; ${ }^{20} \mathrm{CHU}$ Nantes, Nantes, France; ${ }^{21}$ University Regensburg, Regensburg, Germany; ${ }^{22}$ Karolinska University Hospital, Stockholm, Sweden; ${ }^{23}$ Bristol Oncology Centre, Bristol, UK; ${ }^{24}$ University of Heidelberg, Heidelberg, Germany; ${ }^{25}$ Comprehensive Cancer Centre, Department of Haematology, Kings College, London, UK and ${ }^{26} \mathrm{Hôpitaux}$ Universitaires de Genève and Faculty of Medicine, University of Geneva, Geneva, Switzerland

\section{Correspondence:}

MARIE ROBIN

marie.robin@aphp.fr

Received: August 24, 2018

Accepted: January 31, 2019.

Pre-published: February 7, 2019.

doi:10.3324/haematol.2018.205211

Check the online version for the most updated information on this article, online supplements, and information on authorship \& disclosures: www.haematologica.org/content/104/9/1782

(C)2019 Ferrata Storti Foundation

Material published in Haematologica is covered by copyright. All rights are reserved to the Ferrata Storti Foundation. Use of published material is allowed under the following terms and conditions:

https://creativecommons.org/licenses/by-nc/4.0/legalcode. Copies of published material are allowed for personal or internal use. Sharing published material for non-commercial purposes is subject to the following conditions:

https://creativecommons.org/licenses/by-nc/4.0/legalcode, sect. 3. Reproducing and sharing published material for commercial purposes is not allowed without permission in writing from the publisher.

\section{ABSTRACT}

A llogeneic hematopoietic stem cell transplant remains the only curative treatment for myelofibrosis. Most post-transplantation events occur during the first two years and hence we aimed to analyze the outcome of 2-year disease-free survivors. A total of 1055 patients with myelofibrosis transplanted between 1995 and 2014 and registered in the registry of the European Society for Blood and Marrow Transplantation were included. Survival was compared to the matched general population to determine excess mortality and the risk factors that are associated. In the 2 -year survivors, disease-free survival was $64 \%$ (60-68\%) and overall survival was $74 \%(71-78 \%)$ at ten years; results were better in younger individuals and in women. Excess mortality was 14\% (8-21\%) in patients aged $<45$ years and $33 \%(13-53 \%)$ in patients aged $\geq 65$ years. The main cause of death was relapse of the primary disease. Graft-versus-host disease (GvHD) before two years decreased the risk of relapse. Multivariable analysis of excess mortality showed that age, male sex recipient, secondary myelofibrosis and no GvHD disease prior to the 2-year landmark increased the risk of excess mortality. This is the largest study to date analyzing long-term outcome in patients with myelofibrosis undergoing transplant. Overall it shows a good survival in patients alive and in remission at two years. However, the occurrence of late complications, including late relapses, infectious complications and secondary malignancies, highlights the importance of screening and monitoring of long-term survivors. 


\section{Introduction}

Myelofibrosis (MF) is a malignant clonal disease that can be classified as either primary or secondary to either essential thrombocythemia (ET) or polycythemia vera (PV). The clinical phenotype of MF is markedly heterogeneous and disease severity can be assessed by a number of different prognostic scoring systems. For example, utilizing the Dynamic International Prognostic Scoring System (DIPSS-PLUS), low, int-1, int-2 and high-risk patients have a median survival of 15 years, 6.5 years, 35 months and 16 months, repectively. ${ }^{1}$ JAK-2 inhibitors, specifically ruxolitinib, which remains the only licensed therapeutic agent in MF, alleviate many symptoms and even possibly increase survival, but they are not considered curative. ${ }^{2-4}$ Only allogeneic hematopoietic stem cell transplantation (HSCT) has been proposed as curative; overall, HSCT has been reported to cure $30-65 \%$ of these patients. ${ }^{5-16}$ One registry paper analyzed the timing to transplant in patients aged $<65$ years and concluded that those with intermediate- 2 or high-risk disease are those who clearly benefit from transplantation strategies. ${ }^{17}$ This analysis included transplant-episodes prior to the ruxolitinib era, and the role of this agent on transplantation strategies remains under debate..$^{18}$ Early mortality (within 2 years) after transplantation is known to be $10-30 \%$, but so far no study has analyzed the outcome of transplanted MF patients after this early period. In contrast, long-term outcome studies have been published for HSCT recipients who have more common disease types, such as acute leukemia, lymphoma, and chronic myeloid leukemia. ${ }^{19-24}$ Understanding the long-term outcome for transplanted MF patients will help to improve monitoring and promote increased awareness of the potential risks of relapse or, indeed, mortality, particularly when compared to the general population.

\section{Methods}

\section{Patient selection}

Only patients from countries for which the population mortality tables are available in a uniform format through the Human Mortality Database, allowing a sex- and agematched comparison, and contributing more than twenty allogeneic transplantations for MF were included in the study. Patients aged $<18$ years and those who were transplanted from an unrelated matched cord blood were excluded. Patients were analyzed at the time of their first allogeneic transplant only. A total of 2,459 patients received a first allogeneic HCT between January 1995 and December 2014 for primary or secondary MF. A total of 1,055 of these 2,459 patients were reported alive and free of their disease at two years after HSCT; these patients were considered for the study and called long-term (disease-free) survivors. These patients were transplanted in 178 centers in 15 countries.

\section{Definitions}

Relapse was defined as disease recurrence. Causes of death were classified as related to relapse if the patient experienced a relapse at any period during follow up. Excess mortality was defined as the difference between mortality observed in the myelofibrosis landmark (LM) cohort and mortality in a matched cohort of the general population.

\section{Statistical analysis}

The end points of interest were overall survival (OS), disease-free survival (DFS), relapse/progression and nonrelapse mortality (NRM) within the first ten years after HSCT for patients alive and disease-free at the 2-year LM after HSCT. For all outcomes, patients were considered to be at risk since this LM. Median follow up was determined using the reverse Kaplan-Meier method. OS was defined as the time since LM until death from any cause, with surviving patients censored at the time of last follow up. Patients still at risk at ten years after HSCT were administratively censored. DFS was defined as time to death or relapse/progression (whichever occurred first). OS and DFS were estimated using the Kaplan-Meier product limit estimation method, and differences in subgroups were assessed by the Log-rank test. The cumulative incidences of relapse/progression (CIR) and NRM were analyzed together in a competing risks framework. ${ }^{25}$ Competing risks analyses were also applied to estimate the incidences of (extensive) chronic graft-versus-host disease (cGvHD) and secondary malignancies, each with the competing event death, at ten years after HSCT. Previous acute GvHD (aGvHD) in the landmark population was quantified as a simple proportion, since all cases of aGvHD occurred prior to the 2-year LM time point. Cox proportional hazards regression was used to assess the impact of potential risk factors on OS, RFS, CIR and NRM. CIR and NRM were analyzed in a competing risks framework in which the cause-specific hazards (CSH) were modeled.

Methods from relative survival were used to estimate the proportion of the deaths observed in our cohort which could be attributed to population causes (population mortality) and which to MF-related causes, including HSCT and pre-treatment (excess mortality). ${ }^{26,27}$ Patients were matched by age, sex and country and year of HSCT to a cohort from the general population, for whom survival information was available in the population tables in the Human Mortality Database (http:// www. mortality.org). The excess hazard of death was defined as the difference between the observed hazard in the patient cohort (this myelofibrosis cohort) and the hazard of the matched general population cohort. For multivariable analyses, we estimated Cox proportional hazards models for the excess hazard of death. Risk factors considered were age, sex, MF classification (primary vs. secondary), conditioning intensity, total body irradiation (TBI), donor type, stem cell source, and previous GvHD (defined as the development of any type of GvHD between transplantation and the 2year LM). All estimates are reported with $95 \%$ confidence intervals. All analyses were performed in SPSS version 23 and R 3.3.0 (https://cran.r-project.org), 'survival', 'cmprsk', 'prodlim' and 'relsurv' packages.

\section{Results}

\section{Characteristics of patients and transplant}

Characteristics of the entire patient cohort and the long-term survivors are shown in Table 1. Long-term survivors were transplanted at a median age of 53.5 years; $837(79 \%)$ patients had primary MF at the time of transplantation, $645(63 \%)$ patients received a reduced intensity regimen, and $471(45 \%)$ were transplanted using an HLA-matched sibling donor. 
Table 1. Patients' and transplant characteristics.

\begin{tabular}{|c|c|c|c|c|}
\hline & \multicolumn{2}{|c|}{ Whole cohort } & \multicolumn{2}{|c|}{ 2-year landmark } \\
\hline & N & $\%$ & N & $\%$ \\
\hline Total number of patients & 2459 & & 1055 & \\
\hline $\begin{array}{l}\text { Disease at time of transplant } \\
\text { Primary myelofibrosis } \\
\text { Secondary myelofibrosis } \\
\text { Transformation into acute leukemia }\end{array}$ & $\begin{array}{l}1904 \\
421 \\
134\end{array}$ & $\begin{array}{l}78 \\
17 \\
5\end{array}$ & $\begin{array}{l}837 \\
188 \\
30\end{array}$ & $\begin{array}{l}79 \\
18 \\
3\end{array}$ \\
\hline $\begin{array}{l}\text { Median age at HSCT, years } \\
<45 \text { years } \\
45-54 \text { years } \\
55-64 \text { years } \\
\geq 65 \text { years }\end{array}$ & $\begin{array}{c}55 \\
355 \\
729 \\
1137 \\
238\end{array}$ & $\begin{array}{l}14 \\
30 \\
46 \\
10\end{array}$ & $\begin{array}{l}53.5 \\
193 \\
351 \\
426 \\
85\end{array}$ & $\begin{array}{l}19 \\
33 \\
40 \\
8\end{array}$ \\
\hline $\begin{array}{l}\text { Interval primary diagnosis and transplant, median } \\
<12 \text { months } \\
\geq 12 \text { months }\end{array}$ & $\begin{array}{c}743 \\
1716 \\
\end{array}$ & $\begin{array}{l}30 \\
70\end{array}$ & $\begin{array}{l}26.7 \\
308 \\
747\end{array}$ & $\begin{array}{l}29 \\
71\end{array}$ \\
\hline $\begin{array}{l}\text { Conditioning regimen } \\
\text { Reduced intensity } \\
\text { Standard } \\
\text { Total body irradiation, Yes } \\
\text { No }\end{array}$ & $\begin{array}{l}1502 \\
877 \\
423 \\
2015\end{array}$ & $\begin{array}{l}63 \\
37 \\
17 \\
83\end{array}$ & $\begin{array}{l}645 \\
378 \\
191 \\
855\end{array}$ & $\begin{array}{l}63 \\
37 \\
18 \\
82\end{array}$ \\
\hline $\begin{array}{l}\text { Source of stem cells } \\
\text { Marrow } \\
\text { Blood }\end{array}$ & $\begin{array}{c}332 \\
2127\end{array}$ & $\begin{array}{l}14 \\
86\end{array}$ & $\begin{array}{l}150 \\
905\end{array}$ & $\begin{array}{l}14 \\
86\end{array}$ \\
\hline Donor type & & & & \\
\hline HLA matched sibling donor & 1022 & 43 & 471 & 45 \\
\hline Other & 1379 & 57 & 565 & 55 \\
\hline
\end{tabular}

N: number; HSCT: hematopoietic stem cell transplantation. Unreported data found for regimen and type of donor but always $<4 \%$.

\section{Outcome and predictors for outcome}

In the entire cohort (2459 patients, without LM), OS and DFS at ten years were $41 \%(95 \% \mathrm{CI}$ : $39-44)$ and $32 \%$ (95\%CI: 30-35). Median follow up in the LM population was 49.7 months $(95 \% \mathrm{CI}$ : 47-52). In the 1,055 long-term survivors, 166 deaths were registered within ten years after HSCT. For all time periods, the most common cause of death was relapse of MF, followed by GvHD and infection, with a higher occurrence of infection-related deaths between 2- and 5-years post-transplant (Table 2). In the LM population, secondary cancers occurred in 34 patients before the landmark and in 87 patients after the landmark. This translated into a cumulative incidence in the LM population without cancer before the LM at ten years of $14 \%(11-18)$ ten years after the transplantation. The most frequent cancer was solid tumor $(70 \%$, of whom 3 breast cancers), followed by acute leukemia or myelodysplastic syndrome (17\%) and lymphoma (9\%).

Grade 2-4 acute GvHD had occurred in $23 \%$ of the LM patients $(n=245)$. Before LM, 56\% (576 patients) of the patients in the LM population had chronic GvHD of whom 263 patients had an extensive chronic GvHD. Among patients without chronic GvHD before the 2-year LM, cumulative incidence of chronic extensive and limited $\mathrm{GvHD}$ were $13 \%$ (8-18) and 9\% (5-12\%), respectively. Ten-year OS and DFS for 2-year survivors were 74\% (71$78 \%)$ and $64 \%$ (60-68\%), respectively (Figure 1). In these patients, relapse incidence and non-relapse mortality ten years after transplant were estimated at $21 \%(17-24 \%)$ and $15 \%(12-18 \%)$ (Figure 1). Risk factors for mortality, DFS and relapse are shown in Table 3. Older age $(P<0.001)$, type of myelofibrosis (higher risk for secondary myelofibrosis, $P=0.01)$, male sex $(P=0.004)$ and no
Table 2. Causes of mortality after two years.

\begin{tabular}{lcccc}
\hline Tears from transplant & \multicolumn{2}{c}{ 2-5 y } & \multicolumn{3}{c}{$>$ >5-10 y } \\
Relapse/progression & 33 & 41 & 30 & 61 \\
Secondary malignancy* & 9 & 11 & 8 & 16 \\
\hline GvHD & 18 & 22 & 9 & 19 \\
Infection & 17 & 21 & 2 & 4 \\
\hline Organ damage/toxicity & 4 & 5 & & \\
Unknown & 28 & & 8 & \\
\hline Total & 109 & & 57 \\
\hline
\end{tabular}

y: years; N: number; GvHD: graft-versus-host disease. *Including post-transplant lymphoproliferative disease.

GvHD before LM $(P=0.02)$ were associated with a significantly higher risk of mortality. Older age $(P=0.033)$, reduced intensity conditioning (RIC) $(P=0.017)$, male sex $(P=0.003)$, donor other than an HLA-matched related donor $(P=0.01)$ and no GvHD before landmark were associated significantly with lower DFS. Use of a donor other than HLA-matched related donor $(P=0.008)$, RIC $(P=0.042)$ and no GvHD occurrence before the landmark $(P<0.001)$ significantly increased the risk of relapse.

\section{Comparison to general population}

The excess mortality of the two-year landmark MF cohort was $21 \%(18-25 \%)$ at ten years; its population mortality was 4\% (4-4.2\%) (Figure 2). Excess mortality was lower in younger patients and in female gender recipients but remained considerably greater than the 
mortality of the matched population (Figure 2). Excess mortality in the younger cohort ( $<45$ years) was $14 \%$ (8$21 \%)$ and population mortality was $1 \%(1-1.1 \%)$ at this age. In contrast, excess mortality in the older cohort $(\geq 65$ years) was $33 \%(13-53 \%)$ and population mortality was $12 \%(10-14 \%)$.

\section{Risk factors for late excess mortality}

A Cox model was developed to estimate the risk factors for excess mortality in the 2-year disease-free survivors. Of note, the interpretation of the influence of variables in this LM model applies to patients alive and free of the disease two years following transplantation. For instance, patients with severe GvHD may not survive the second year post-transplant but the subset of patients who survived with severe GvHD are incorporated in the model. The multivariable model shows that older age, MF secondary to PV or ET, male gender recipient were risk factors for excess mortality (Table 4). In long-term survival, previous GvHD was protective for mortality (Table 4). The model highlights that age and sex, which were at higher risk in the general model, are still risk factors for excess mortality. Figure 3 shows changes in the hazard of excess mortality of reference patients according
A

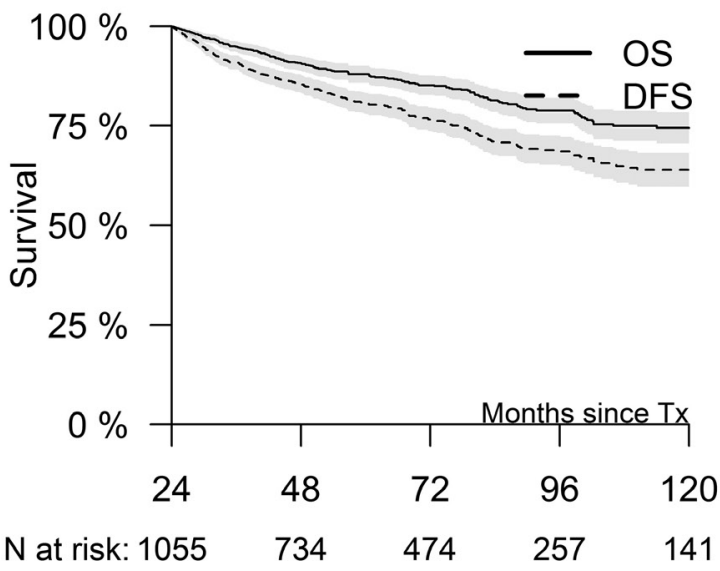

B

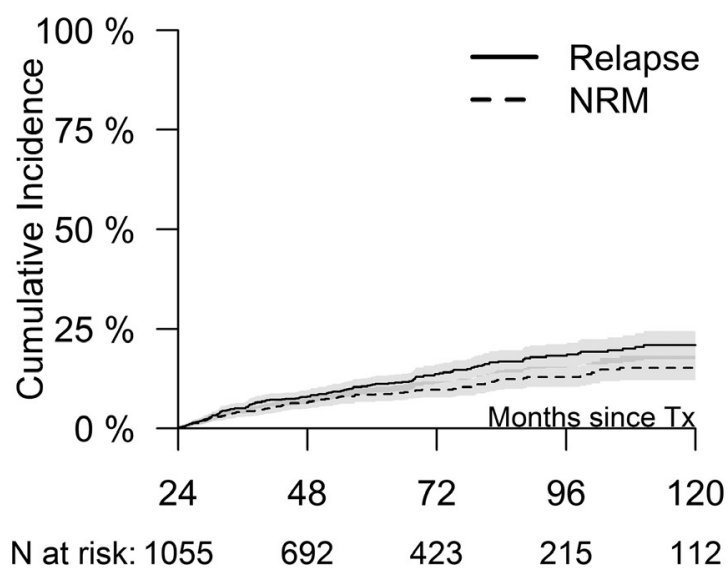

Figure 1. Outcome of myelofibrosis patient from landmark time. (Left) Overall survival (OS; solid line) and disease-free survival (DFS: dashed line) from landmark time. (Right) Incidence of relapse (solid line) and non-relapse mortality (NRM) (dashed line). N: number; Tx: transplant.

Table 3. Multivariable (cause-specific) Cox proportional hazards models for outcomes in the period between two and ten years after hematopoietic stem cell transplantation for patients alive and disease-free at two years after hematopoietic stem cell transplantation.

\begin{tabular}{|c|c|c|c|c|c|c|}
\hline Variables & $\begin{array}{c}\text { Overall survival } \\
\text { HR (95\%Cl) }\end{array}$ & $P$ & $\begin{array}{c}\text { Disease-free survival } \\
\text { HR (95\%Cl) }\end{array}$ & $P$ & $\begin{array}{l}\text { Relapse } \\
\text { HR (95\%CI) }\end{array}$ & $P$ \\
\hline Age (per decade) & $1.45(1.19-1.76)$ & $<0.001$ & $1.18(1.01-1.37)$ & 0.033 & $1.16(0.96-1.42)$ & 0.131 \\
\hline $\begin{array}{l}\text { Patient sex } \\
\text { Male } \\
\text { Female } \\
\end{array}$ & $\begin{array}{c}1 \\
0.58(0.4-0.84)\end{array}$ & 0.004 & $\begin{array}{c}1 \\
0.65(0.49-0.87)\end{array}$ & 0.003 & $\begin{array}{c}1 \\
0.79(0.55-1.14)\end{array}$ & 0.205 \\
\hline $\begin{array}{l}\text { MF classification } \\
\text { PMF } \\
\text { SMF }\end{array}$ & $\begin{array}{c}1 \\
1.66(1.13-2.44)\end{array}$ & 0.01 & $\begin{array}{c}1 \\
1.35(0.97-1.88)\end{array}$ & 0.071 & $\begin{array}{c}1 \\
1.07(0.67-1.7)\end{array}$ & 0.78 \\
\hline $\begin{array}{l}\text { Source of stem cells } \\
\text { Marrow } \\
\text { PB }\end{array}$ & $\begin{array}{c}1 \\
0.83(0.51-1.34)\end{array}$ & 0.442 & $\begin{array}{c}1 \\
0.77(0.52-1.13)\end{array}$ & 0.178 & $\begin{array}{c}1 \\
0.67(0.41-1.09)\end{array}$ & 0.107 \\
\hline $\begin{array}{l}\text { Conditioning regimen } \\
\text { MAC } \\
\text { RIC }\end{array}$ & $\begin{array}{c}\text { intensity } \\
1 \\
1.17(0.79-1.73)\end{array}$ & 0.434 & $1.48(1.07-2.04)$ & 0.017 & $\begin{array}{c}1 \\
1.54(1.02-2.35)\end{array}$ & 0.042 \\
\hline $\begin{array}{l}\text { Conditioning regimer } \\
\text { Chemo only } \\
\text { TBI }\end{array}$ & $\begin{array}{l}\text { with } \\
1.25(0.81-1.93)\end{array}$ & 0.322 & $\begin{array}{c}1 \\
1.28(0.89-1.82)\end{array}$ & 0.18 & $\begin{array}{c}1 \\
1.28(0.8-2.06)\end{array}$ & 0.305 \\
\hline $\begin{array}{l}\text { Type of donor } \\
\text { Matched sibling } \\
\text { Unrelated }\end{array}$ & $\begin{array}{c}\mathbf{1} \\
1.08(0.77-1.51)\end{array}$ & 0.669 & $\begin{array}{c}1 \\
1.43(1.09-1.89)\end{array}$ & 0.011 & $\begin{array}{c}1 \\
1.65(1.14-2.39)\end{array}$ & 0.008 \\
\hline Any previous GvHD & $0.67(0.48-0.94)$ & 0.02 & $0.62(0.47-0.81)$ & 0.001 & $0.42(0.3-0.6)$ & $<0.001$ \\
\hline
\end{tabular}

HR: Hazard Ratio; CI: Confidence Interval; MF: myelofibrosis; PMF: primary myelofibrosis; SMF: secondary myelofibrosis; PB: peripheral blood; MAC: myeloablative conditioning; RIC: reduced intensity conditioning; TBI: total body irradiation; GvHD: graft-versus-host disease.Variables that are significantly associated with the risk are in bold. 
to Cox model (variables from Table 4) transplanted at the age of 50 years; the hazards are given for men and for women separately. We can see that there is a decline in hazard of excess mortality over time post HSCT, but after three years ( 5 years post-transplant), there is a plateau.

\section{Discussion}

This EBMT report of 1,055 patients alive and in remission at two years after HSCT is the largest study of longterm post-transplant outcome in patients with MF. Results indicate that survival ten years after transplantation in these 2 -year survivors is $74 \%$, but also that the

A
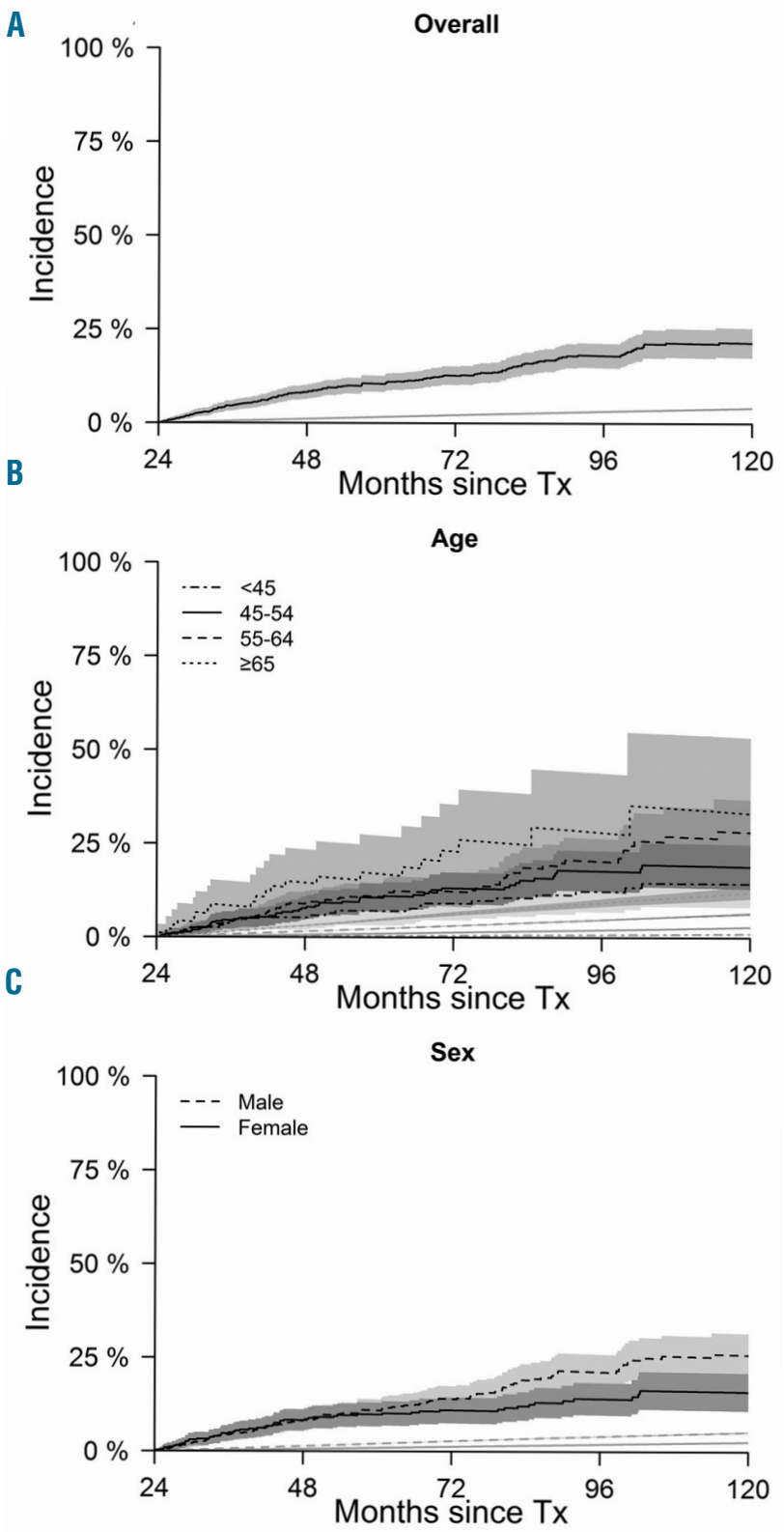

Figure 2. Mortality in myelofibrosis compared to the general population. (Top) Plots show mortality of the disease-free survivors (black line) and of the general population (gray line). (Middle) Plots show mortality of the myelofibrosis patients according to sex (black solid line: female; dashed line: male) and mortality in the general population (gray lines). (Bottom) Plots show mortality of disease-free survivors (black lines) and general population (gray lines) according to age categories. Tx: transplantation. mortality rate does not decrease to that expected in the general population. This is the first long-term study in MF using LM analytical methods. It had previously been reported in other diseases that long-term outcome in transplanted patients remains lower than expected in the general population (except in aplastic anemia). ${ }^{20,21}$ Our results can be considered disappointing as compared to previous publications, especially from the Center for International Blood and Marrow Transplant Research, ${ }^{20}$ but the median age was two decades higher in our cohort, which could explain the higher long-term mortality. Indeed, we could confirm that in a subgroup of patients aged under 45 years, OS was very good at $86 \%$ ten years after transplantation. Two additional recent long-term analyses in patients with chronic malignancies [chronic lymphocytic leukemia (CLL) and myelodysplastic syndrome (MDS)] from the EBMT registry included patients with a median age closer to MF patients estimated, with long-term survival lower than in this MF cohort. ${ }^{27,24}$ Similar risk factors for mortality were found with a better OS in women and in younger ${ }^{24}$ patients. The reason for the higher risk in male recipients is not clear but it is usually thought to be due to behaviors which place the patient at higher risk, and also to a higher propensity towards comorbidities such as cardio-vascular disease. ${ }^{28}$ In contrast, an EBMT study of patients with acute myeloid leukemia did not show age or sex to be predictors for OS..$^{29}$

Like in other malignant disorders, late relapse was the leading cause of death in MF patients following HSCT. ${ }^{19}$ $22,24,29$ Incidence of relapse at ten years after transplant in the long-term survivors is $21 \%$, in agreement with that expected in other malignant disorders. This highlights the fact that, even if the relapse risk decreases over time, it

Table 4. A multivariable Cox proportional hazards model for excess mortality in the period between two and ten years after hematopoietic stem cell transplantation for patients alive and disease-free at two years after hematopoietic stem cell transplantation.

\begin{tabular}{lccc} 
& Hazard ratio & $\begin{array}{c}95 \% \text { confidence } \\
\text { interval }\end{array}$ & $P$ \\
$\begin{array}{l}\text { Patient sex } \\
\text { Male }\end{array}$ & 1 & & \\
Female & 0.62 & $0.41-0.93$ & 0.022 \\
Age (per decades) & 1.35 & $1.08-1.69$ & 0.008 \\
\hline $\begin{array}{l}\text { Disease } \\
\text { Primary myelofibrosis }\end{array}$ & 1 & & \\
$\quad$ Secondary myelofibrosis & 1.81 & $1.18-2.78$ & 0.007 \\
$\begin{array}{l}\text { Conditioning regimen } \\
\text { Standard }\end{array}$ & 1 & & \\
Reduced intensity regimen & 1.16 & $0.74-1.82$ & 0.527 \\
\hline $\begin{array}{l}\text { No TBI } \\
\text { TBI in regimen }\end{array}$ & 1 & & \\
$\begin{array}{l}\text { Donor } \\
\text { Matched sibling donor }\end{array}$ & 1.25 & $0.75-2.08$ & 0.384 \\
Other donor & 1 & & \\
\hline $\begin{array}{l}\text { Source of stem cells } \\
\text { Marrow }\end{array}$ & 1.1 & $0.75-1.63$ & 0.623 \\
$\begin{array}{l}\text { Blood } \\
\text { GvHD } \\
\text { No } \\
\text { Any }\end{array}$ & 1 & & \\
\hline
\end{tabular}

TBI: total body irradiation; GvHD: graft-versus-host disease. 
can still occur late after transplant. Many studies have reported that relapse risk is related to the disease risk at the time of transplant; unfortunately, due to the retrospective registry-based nature of this study, we did not have sufficient data to calculate a relevant International Prognostic Scoring System so this could not be analyzed. However, we observed that the relapse risk was higher in patients who received a RIC, which could be expected. We were, however, surprised that in long-term survivors, the intensity of the regimen still had some impact. In acute myeloid leukemia, the EBMT long-term study did not find that regimen intensity still influences late relapse. ${ }^{29}$ Occurrence of acute or chronic GvHD before the LM was the strongest factor preventing relapse in long-term survivors. While in many other studies GvHD increased the risk of late deaths, we failed to confirm this in our MF cohort. ${ }^{19,20} \mathrm{GvHD}$ before LM (2 years) in longterm survivors was protective for both relapse risk as well as for mortality. Of course, from this analysis, we cannot extrapolate data confirming that $\mathrm{GvHD}$ is needed to improve long-term outcome, because patients with GvHD leading to death in the first two years of transplant had been excluded from the study.

The weakness for GvHD analysis within this cohort was that we could not delineate the risk of "active GvHD" because we had no data regarding GvHD resolution, although it is probable that patients still alive at two years with chronic GvHD were those with the less severe GvHD. The vast majority of patients had onset of chronic GvHD before the LM, but some patients had also a late onset. Finally, the majority of survivors suffered (or had suffered) from chronic GvHD which may alter their quality of life, and it is noteworthy that, even if they are in remission from their $\mathrm{MF}$, patients could have a chronic GvHD which can be a cause of death particularly before five years.

Infectious complications remained a frequent cause of death between two and five years post transplant. It has previously been reported that splenectomy before transplant increased the risk of late severe infection which may in part contribute to these findings within the MF cohort. ${ }^{30}$ This high risk of lethal infection should be taken into account in long-term monitoring strategies and highlights the importance of appropriate anti-infective prophylaxis. ${ }^{31,32}$

Second malignancies were also the cause of very late

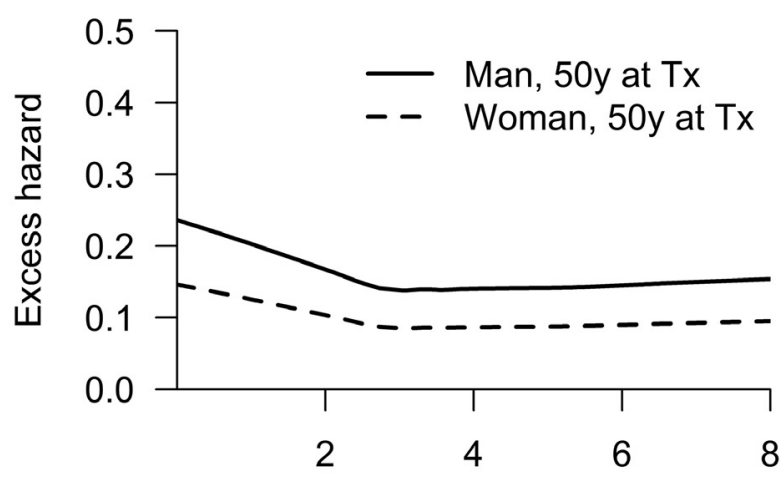

Years since landmark

Figure 3. Hazard rate for excess risk of mortality over time post transplant. Curves show hazard rates for two reference patients, based on the Cox model for the excess hazard. They were both 50 years (y) of age at time of hematopoietic stem cell transplantation (Tx), had primary myelofibrosis, received standard conditioning, did not receive total body irradiation, had a matched sibling donor, marrow was source of stem cells, and had no previous graft-versus-host disease. Solid line: male patient; dashed line: female patient.

deaths, justifying long-term monitoring and cancer prevention in this population. After five years, $16 \%$ of deaths were due to second malignancies, and at ten years, cumulative incidence of secondary cancer was $14 \%$. We could not analyze specific risk factors for second malignancies due to the small numbers involved. There are few long-term survivors for non-transplanted higher risk $\mathrm{MF}$ so there are no data for long-term secondary cancers within that population and risk factors are unknown. It is hard to determine how the transplantation process increases the risk of cancer, but chemotherapy, radiotherapy, immune deficiency, chronic GvHD, genetic susceptibility as well as age can cumulatively contribute towards an increased susceptibility.

In conclusion, patients with MF have good survival when alive and in remission two years after transplantation, especially younger and female recipients. Severe late complications and late relapses should be monitored and prevention highlighted in order to reduce life-threatening complications. Lifelong follow up is required to optimize long-term outcomes. ${ }^{33}$

\section{References}

1. Gangat N, Caramazza D, Vaidya R, et al. DIPSS Plus: A Refined Dynamic International Prognostic Scoring System for Primary Myelofibrosis That Incorporates Prognostic Information From Karyotype, Platelet Count, and Transfusion Status. J Clin Oncol. 2011;29(4):392-397.

2. Verstovsek S, Mesa RA, Gotlib J, et al. A double-blind, placebo-controlled trial of ruxolitinib for myelofibrosis. N Engl J Med. 2012;366(9):799-807.

3. Verstovsek S, Mesa RA, Gotlib J, et al. Efficacy, safety and survival with ruxolitinib in patients with myelofibrosis: results of a median 2-year follow-up of COMFORT-I. Haematologica. 2013;98(12):1865-1871.
4. Verstovsek S, Mesa RA, Gotlib J, et al. Longterm treatment with ruxolitinib for patients with myelofibrosis: 5 -year update from the randomized, double-blind, placebo-controlled, phase 3 COMFORT-I trial. J Hematol Oncol. 2017;10(1):55.

5. Guardiola P, Anderson JE, Bandini G, et al. Allogeneic stem cell transplantation for agnogenic myeloid metaplasia: a European Group for Blood and Marrow Transplantation, Société Française de Greffe de Moelle, Gruppo Italiano per il Trapianto del Midollo Osseo, and Fred Hutchinson Cancer Research Center Collaborative Study. Blood. 1999;93(9):2831-2838.

6. Kerbauy DMB, Gooley TA, Sale GE, et al. Hematopoietic cell transplantation as curative therapy for idiopathic myelofibrosis, advanced polycythemia vera, and essential thrombocythemia. Biol Blood Marrow Transplant. 2007;13(3):355-365.

7. Patriarca F, Bacigalupo A, Sperotto A, et al. Allogeneic hematopoietic stem cell transplantation in myelofibrosis: the 20-year experience of the Gruppo Italiano Trapianto di Midollo Osseo (GITMO). Haematologica. 2008;93(10):1514-1522.

8. Kröger N, Holler E, Kobbe G, et al. Allogeneic stem cell transplantation after reduced-intensity conditioning in patients with myelofibrosis: a prospective, multicenter study of the Chronic Leukemia Working Party of the European Group for Blood and Marrow Transplantation. Blood. 2009;114 (26):5264-5270

9. Ballen KK, Shrestha S, Sobocinski KA, et al. Outcome of transplantation for myelofibrosis. Biol Blood Marrow Transplant J Am Soc 
Blood Marrow Transplant. 2010;16(3):358367.

10. Robin M, Tabrizi R, Mohty M, et al. Allogeneic haematopoietic stem cell transplantation for myelofibrosis: a report of the Société Française de Greffe de Moelle et de Thérapie Cellulaire (SFGM-TC). Br J Haematol. 2011;152(3):331-339.

11. Gupta V, Malone AK, Hari PN, et al. Reduced-intensity hematopoietic cell transplantation for patients with primary myelofibrosis: a cohort analysis from the center for international blood and marrow transplant research. Biol Blood Marrow Transplant. 2014;20(1):89-97.

12. Rondelli D, Goldberg JD, Isola L, et al. MPDRC 101 prospective study of reduced-intensity allogeneic hematopoietic stem cell transplantation in patients with myelofibrosis. Blood. 2014;124(7):1183-1191.

13. Ditschkowski M, Elmaagacli AH, Trenschel $\mathrm{R}$, et al. Dynamic International Prognostic Scoring System scores, pre-transplant therapy and chronic graft-versus-host disease determine outcome after allogeneic hematopoietic stem cell transplantation for myelofibrosis. Haematologica. 2012;97(10): 1574-1581.

14. Deeg HJ, Gooley TA, Flowers MED, et al. Allogeneic hematopoietic stem cell transplantation for myelofibrosis. Blood. 2003; 102(12):3912-3918

15. Scott BL, Gooley TA, Sorror ML, et al. The Dynamic International Prognostic Scoring System for myelofibrosis predicts outcomes after hematopoietic cell transplantation. Blood. 2012:119(11):2657-2664.

16. Samuelson Bannow BT, Salit RB, Storer BE, et al. Hematopoietic Cell Transplantation for Myelofibrosis: the Dynamic International Prognostic Scoring System Plus Risk Predicts Post-Transplant Outcomes. Biol Blood Marrow Transplant. 2018;24(2): 386-392

17. Kröger N, Giorgino T, Scott BL, et al. Impact of allogeneic stem cell transplantation on survival of patients less than 65 years of age with primary myelofibrosis. Blood. 2015;125(21):3347-3350; quiz 3364

18. Cervantes F, Pereira A. Does ruxolitinib prolong the survival of patients with myelofibrosis? Blood. 2017;129(7):832-837.

19. Socié G, Stone JV, Wingard JR, et al. Longterm survival and late deaths after allogeneic bone marrow transplantation. Late Effects Working Committee of the International Bone Marrow Transplant Registry. N Engl I Med. 1999;341(1):14-21.

20. Wingard JR, Majhail NS, Brazauskas R, et al. Long-term survival and late deaths after allogeneic hematopoietic cell transplantation. Clin Oncol. 2011;29(16):2230-2239.

21. Goldman JM, Majhail NS, Klein JP, et al Relapse and late mortality in 5-year survivors of myeloablative allogeneic hematopoietic cell transplantation for chronic myeloid leukemia in first chronic phase. J Clin Oncol. 2010;28(11):1888-1895.

22. Martin PJ, Counts GW, Appelbaum FR, et al. Life expectancy in patients surviving more than 5 years after hematopoietic cell transplantation. J Clin Oncol. 2010;28(6):1011 1016.

23. Bhatia S, Francisco L, Carter A, et al. Late mortality after allogeneic hematopoietic cell transplantation and functional status of long-term survivors: report from the Bone Marrow Transplant Survivor Study. Blood. 2007:110(10):3784-3792.

24. van Gelder M, de Wreede LC, Bornhäuser $M$, et al. Long-term survival of patients with CLL after allogeneic transplantation: a report from the European Society for Blood and Marrow Transplantation. Bone Marrow Transplant. 2017;52(3):372-380.

25. Iacobelli S; EBMT Statistical Committee. Suggestions on the use of statistical methodologies in studies of the European Group for Blood and Marrow Transplantation. Bone Marrow Transplant. 2013;48 Suppl 1S1-37.
26. Pohar Perme $M$, Estève I, Rachet $B$. Analysing population-based cancer survival - settling the controversies. BMC Cancer. 2016;16(1):933

27. Schetelig J, de Wreede LC, van Gelder M, et al. Late treatment-related mortality versus competing causes of death after allogeneic transplantation for myelodysplastic syndromes and secondary acute myeloid leukemia. Leukemia. 2019;33(3):686-695.

28. Pophali PA, Klotz JK, Ito S, et al. Male survivors of allogeneic hematopoietic stem cell transplantation have a long term persisting risk of cardiovascular events. Exp Hematol. 2014;42(2):83-89.

29. Shimoni A, Labopin M, Savani B et al Long-term survival and late events after allogeneic stem cell transplantation from HLAmatched siblings for acute myeloid leukemia with myeloablative compared to reduced-intensity conditioning: a report on behalf of the acute leukemia working party of European group for blood and marrow transplantation. J Hematol Oncol. 2016;9 (1):118.

30. Robin M, Porcher R, De Castro Araujo R, et al. Risk factors for late infections after allogeneic hematopoietic stem cell transplantation from a matched related donor. Biol Blood Marrow Transplant. 2007;13(11): 1304-1312.

31. Syrjala KL, Martin PJ, Lee SJ. Delivering care to long-term adult survivors of hematopoietic cell transplantation. J Clin Oncol. 2012; 30(30):3746-3751

32. Majhail NS, Rizzo JD, Lee SJ, et al Recommended screening and preventive practices for long-term survivors after hematopoietic cell transplantation. Rev Bras Hematol Hemoter. 2012;34(2):109-133.

33. Bhatia S, Armenian SH, Landier W. How I monitor long-term and late effects after blood or marrow transplantation. Blood. 2017;130(11):1302-1314. 